\title{
Geometrical Aspects on Bi-Material Microtensile Tests
}

and R. Y. Ballester

Department of Dental Materials

University of São Paulo

São Paulo, S.P. Brazil

jo@usp.br

and ryb@usp.br

\section{R. G. Lima}

and R. Martins de Souza

Department of Mechanical Engineering

University of São Paulo

São Paulo, S.P. Brazil

rauglima@usp.br

and roberto.souza@poli.usp.b

L. Driemeier

Department of Mechatronics and Mechanical System Engineering

University of São Paulo

São Paulo, S.P. Brazil

larissa.driemeier@poli.usp.br
Recently the bond strength of composite resin to tooth has received attention from researchers of dental materials. Limitations imposed by the biological substrate, such as the size of the specimen, fostered the development of a tensile test with small dimensions. Due to the reduced size of the specimens, the test is called microtensile test. The specialized literature has not presented standards for the test parameters and the relatively large scatter of published bond strength data probably reflects the lack of standards for the test parameters. The objective of this study is to evaluate how specimen geometry and loading conditions affect the estimation of bond strength. A numerical simulation of the test using a Finite Element Model was performed to determine the associated variations on the stress field imposed by variations in the geometry of the specimen and loading conditions. The Finite Element pre-processing and post-processing was performed on Patran ${ }^{\circledR}$ and the Finite Element processing was performed on Marc ${ }^{\circledR}$. Results from numerical simulations show that geometrical parameters and loading conditions have a significant influence on the stress field. Some suggestions of standards for the microtensile test considering the non-uniform stress field are presented.

Keywords: Finite element, stress concentration, microtensile test

\section{Introduction}

In the last few years, bonding to dental structures has received great attention by researchers. The objective of this study was to evaluate some geometrical and loading conditions that might interfere in the stress concentration of specimens submitted to microtensile bond strength test by means of Finite Element Modelling.

Improvements in adhesive dentistry, especially with regard to the development of materials with high bond strength to dental tissues, brought important modifications to the clinical practice. More conservative treatments were introduced with bonded restorations, which do not require removal of sound dental structures, since mechanical retentions are not practically necessary. However, the development of mechanical tests to provide data on the bond strength of these new dental materials and techniques presents some difficulties:

1. Specimen shape and size: in several mechanical tests performed in Engineering, the specimen size and shape can be designed to provide uniform stress distribution. However, in the specific case of tooth bond strength tests, specimens present limitations in terms of shape and size, because a biological substrate is employed.

2. Intra and inter-tooth differences: specimen standardization is sometimes difficult to be achieved because of the heterogeneity of size and shape among teeth (even in a same group, for instance, molar teeth), and structural/constitutive variations in the same tooth (enamel thickness, degree if mineralization of dentin, among others).

3. Difficulties in obtaining teeth: standardized teeth (especially human teeth) are usually difficult to be obtained in a large number, specially if parameters of standardization are rigidly followed, such

Paper accepted June, 2005. Technical Editor: Atila P. Silva Freire. as tooth age, post-extraction aging, storage means and conditions, etc.

Due to these and other difficulties, and to the necessity of adapting the methodology to the work purpose and laboratory conditions available, different mechanical tests can be found to evaluate bond strength to tooth structures. Shear and tensile are the tests traditionally used for this purpose. For both tests, one of the tooth surfaces is flattened and this flattened area is subjected to the bonding procedure. Oilo (1993) and Watanabe and Nakabayashi (1994) emphasized the problem that shear bond strength tests easily become into bending test, thus resulting in erroneous values. The shear bond strength test, which was commonly employed due to its relative simple accomplishment, was then disqualified, since it was recently demonstrated that its stress distribution would affect the substrate much more than the bonded interface, resulting in a large number of cohesive failures (DeHoff, Anusavice and Wang (1995)). This phenomenon was demonstrated in a Finite Element study conducted by Versluis, Tantbirojn and Douglas (1997).

On the other hand, in the tensile test methodology there is a difficulty in aligning the parts during bonding to the test devices, to guarantee an uniform axial load distribution during testing (Oilo (1993, Sudsangiam and van Noort (1999, Van Noort et al. (1989, Van Noort et al. (1991)). Moreover, several cohesive fractures were observed in dentin during tensile tests.

Sano et al. (1994) developed a new methodology to obtain the ultimate tensile bond strength to human and bovine dentin using very small hour-glass or dumbbell shaped specimens. In this case, during the analysis, stress concentration theoretically occurs at the necking zone, i.e., the zone of smallest cross section, avoiding the cohesive fracture.

Stress concentration is very important since the rupture process in brittle materials is dominated by microcracks nucleation and growth. The final process is the unstable propagation of a macrocrack that nucleated in a region of high stress level, which was determined by loading characteristics, geometry and the 
presence of a bi-material interface. Moreover, the higher the stress concentration, the lower and less representative the calculated nominal stress (ratio between load and smallest cross sectional area) will be (Meira et al. (2004)).

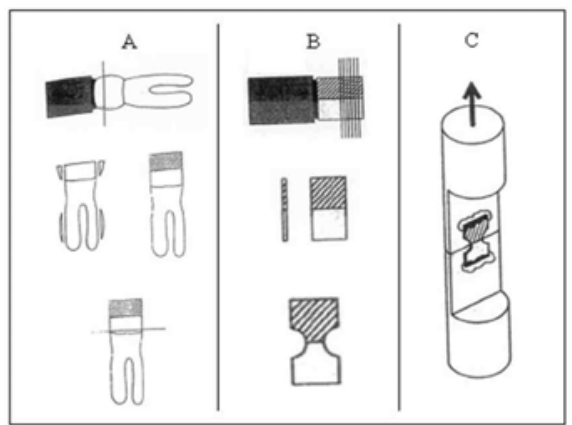

Figure 1. Schematic illustration of the arrangement of the specimens for bond strength tests (Modified from Sano et al. (1994)). (A) occlusal flattening, bonding procedure at the surface and construction of a block of composite resin; (B) Longitudinal cut to obtain slices of about $7 \mathrm{~mm}$ thick and confection of the notch, leaving a cross section of about $1 \mathrm{~mm} 2$; (C) Specimen glued to the jig to tensile test.

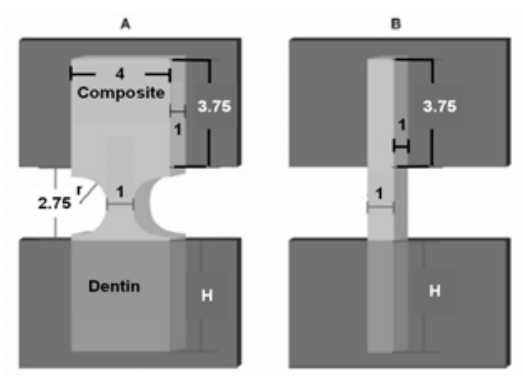

Figure 2. Geometrical characteristics of (A) hour-glass and (B) stick shaped specimens.

The first microtensile bond strength test attempted to evaluate the ultimate dentin tensile bond strength, and the method then started to be largely employed to test bonding efficacy. The first published study with this purpose was also performed by Sano et al. (1994) who used hour-glass shaped specimens (Figure 1).

A point that was greatly emphasized by the authors was the reduced number of cohesive failures with this new method when compared to conventional shear and tensile bond strength tests. This was mainly attributed to the facility in aligning the specimens, and consequently to a better axial distribution of stresses. However, it was not considered that the notch could possibly result in a stress concentration in the tested adhesive interface, which in fact provoked the occurrence of an adhesive fracture, although under non-uniform stress.

Since then, the microtensile bond strength test has been considered as the most effective mechanical test to study bond strength in Dentistry (Pashley et al. (1999)). The reduced frequency of cohesive failures, associated with other advantages achieved with this methodology, quickly made this test accepted among different dental research centers. However, despite its advantages, the lack of standardization in most of the geometric parameters of this test, such as the mode of fixation to the jigs, may lead to a great variety in stress distribution, thus making it difficult to compare results obtained by different authors.

\section{To Summarize:}

1. The authors do not usually consider that the presence of an increased stress concentration occurring in the area of smallest cross-section in hour-glass-shaped specimens is accompanied by a stress concentration that would make them non-uniform (due to the notch and other geometric and loading aspects inherent to the analysis). This lack of uniformity may also influence values of nominal stress;

2. There is a great lack of standards for the specimen geometrical parameters that may collaborate to the discrepancy among results obtained by different authors;

3. This lack of standardized geometrical parameters sometimes occurs in the same work, and may generate errors of data interpretation.

This study contributes to an understanding of the parameters that should be standardized when performing microtensile stress tests to assess bond strength of adhesive materials using dentin/composite specimens.

\section{Material and Methods}

The two most frequently employed specimen shapes for microtensile bond strength testing were simulated in this study: hour-glass and stick shaped specimens (see Figure 2).

The hour-glass-shaped specimens were analyzed with different curvature radius of the notch $(\mathrm{r}=0.2,0.5,0.7$ and $1 \mathrm{~mm})$, with constant area of the smallest cross section $\left(1 \mathrm{~mm}^{2}\right)$ and with specimen width of $4 \mathrm{~mm}$. The cross sectional area for the stickshaped specimens was also $1 \mathrm{~mm}^{2}$.

Each specimen was composed by two different materials: composite resin (with Young Modulus E=20.5 GPa and Poisson coefficient $\mu=0.31$ ) and dentin (with Young Modulus E=15 GPa and Poisson coefficient $\mu=0.24$ ). The simulation represented the most common experimental analysis, where both dentin and composite resin are bonded to the jig at only one face of the specimen. For each specimen shape, two simulations were conducted, changing the height of bonded dentin, thus simulating actual cases, in which the amount of remaining dentin is very short, such as in deep dentin. In this way, the height of the bonded composite is constant h_c =3.75 mm while the height of bonded dentin is $h_{d}=1 \mathrm{~mm}$ or $h_{d}=3.75 \mathrm{~mm}$.

The finite element pre-processing and post-processing were performed with Patran ${ }^{\circledR}$, while the finite element processing was performed on Marc ${ }^{\circledR}$, both well-known commercial finite element software. Figure 3 shows the boundary conditions and the load applied to the nodes of the surface at which the specimen would be glued to the jig.

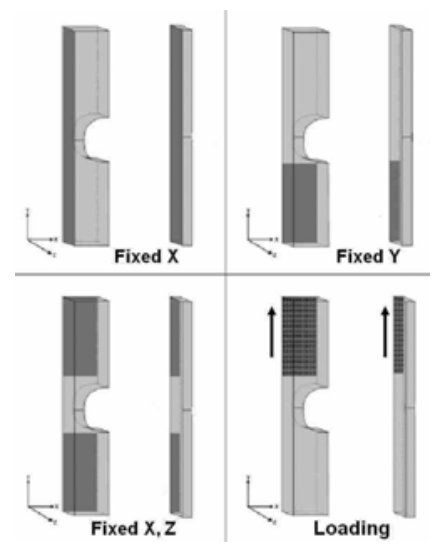

Figure 3. Boundary conditions to hour-glass and stick shaped specimen. 
Two factors were used to analyze the differences between stress states obtained in each case:

$\mathrm{K}_{\mathrm{t}}$ - stress concentration factor - presents the ratio between the maximum tensile stress and the nominal tensile stress. According to the common concept, a $\mathrm{K}_{\mathrm{t}}$ different from one only exists when there is a geometrical discontinuity (notch, hole, etc.). In this study we are using an amplified concept of $\mathrm{K}_{\mathrm{t}}$, as we are considering the relationship between nominal and maximum stresses, despite its cause, which in several cases can be related to the mode of loading or to the discontinuity in specimen properties.

$\mathrm{K}_{\mathrm{f}}$ - defined as the ratio between the maximum tensile stress outside the interface and the maximum tensile stress at the interface. We considered that the higher the $\mathrm{K}_{\mathrm{f}}$ value, the higher the tendency for the occurrence of cohesive fracture in the substrate.

\section{Numerical Results}

Table 1. Presents the values of $\mathrm{Kt}$ and $\mathrm{Kf}$ for all the simulations conducted in this work.

\begin{tabular}{|c|c|c|c|c|c|}
\hline \multicolumn{2}{|l|}{ Shape } & \multirow{2}{*}{ hd } & \multirow{2}{*}{$\mathrm{Kt}$} & \multirow{2}{*}{ Kf } & \multirow{2}{*}{ Row* } \\
\hline \multirow{9}{*}{ Hour-glass } & $\mathrm{r}$ & & & & \\
\hline & \multirow{2}{*}{0.2} & 1.0 & 2.9 & 1.0 & $\overline{1} 1$ \\
\hline & & 3.75 & 2.7 & 1.0 & 2 \\
\hline & \multirow{2}{*}{0.5} & 1.0 & 1.9 & 1.0 & 3 \\
\hline & & 3.75 & 1.8 & 1.0 & 4 \\
\hline & \multirow{2}{*}{0.7} & 1.0 & 1.8 & 1.1 & 5 \\
\hline & & 3.75 & 1.6 & 1.0 & 6 \\
\hline & \multirow{2}{*}{1.0} & 1.0 & 1.6 & 1.3 & 7 \\
\hline & & 3.75 & 1.5 & 1.1 & 8 \\
\hline \multirow{2}{*}{ Stick } & & 1.0 & 1.5 & 2.0 & 9 \\
\hline & & 3.75 & 1.3 & 2.2 & 10 \\
\hline Column* & & & A & $\mathrm{B}$ & \\
\hline
\end{tabular}

The results show that for all specimens with hour-glass shape, the value for $K_{t}$ increases as the radius of curvature decreases. The height of bonded dentin $h_{d}$ influences both the hour-glass and stick shaped specimens: $K_{t}$ increases as the height of bonded region decreases. The highest value for $K_{t}$ is obtained for the hour-glass specimen with radius $\mathrm{r}=0.2 \mathrm{~mm}$ and $h_{d}=1 \mathrm{~mm}$ (cell A1, Table $1-\mathrm{K}_{\mathrm{t}}$ $=2.9$ ). It is worth noting that only hour-glass specimens with radius $\mathrm{r}=1 \mathrm{~mm}$ and $h_{d}=1 \mathrm{~mm}$ leads to a value of $\mathrm{K}_{\mathrm{f}}$ significantly different from unity. However, all analysis with stick specimens have high values for $\mathrm{K}_{\mathrm{f}}$.

\section{Discussion}

In Engineering, tensile tests are traditionally conducted with specimens that guarantee uniaxial stress state, leading to a nominal tensile strength coincident with the maximum tensile stress. In the tests conducted in Dentistry, however, stress concentrations are induced by geometric and loading limitations imposed by the biological material. In the last case, due to stress concentration, the nominal tensile strength can not be representative for the bond strength, justifying the study through $\mathrm{K}_{\mathrm{t}}$.

Moreover, we introduced another index, denominated here as $\mathrm{K}_{\mathrm{f}}$, which help us to predict the occurrence of cohesive fractures. It is clear that when the maximum tensile stress does not occur at the interface, the probability of cohesive fracture increases. An increasing probability of cohesive fracture is found for an increasing relation between maximum stress at the specimen and the maximum stress at the interface, i.e., increasing $\mathrm{K}_{\mathrm{f}}$.

The hour-glass is the most common shape found in the literature for microtensile test. In the most recent, works the authors tend to restrict the cross sectional area at the neck to about $1 \mathrm{~mm}^{2}$.
However, other important geometric parameters, such as the radius of curvature, present a considerable variation. The review made by Pashley et al. (1999) shows notches varying from a narrow slot to a smooth curvature (Figure 4). Comparing cells A2, A4, A6 and A8, in Table 1 , it is clear that the radius plays a significant role in the stress concentration and, consequently, in the experimental maximum nominal strength. It is therefore not correct to directly compare nominal strengths from publications of experimental analysis with different curvature radii.

Comparing cells A1 and A2, A3 and A4, up to A9 and A10, in Table 1 , it is possible to observe that another geometric parameter that significantly influences the value of $K_{\mathrm{f}}$ is the height of bonded dentin. Variations in the values of $h_{d}$ occur in works from different authors and also in the same work, leading to a doubtful validity of the conclusions. Variations of $h_{d}$ occur mainly because of variations on the thickness of remaining dentin throughout the teeth. Sometimes, the authors intend to study the bond strength in different regions of the dentin (superficial dentin - near to the enamel versus deep dentin - near to the pulp chamber).

Some authors (Inoue et al. (2001)) found lower nominal strength values for deep dentin than for superficial dentin. Nevertheless, since the specimens with deep dentin present a smaller $h_{d}$ than with superficial dentin, the explanation for the difference between union strength of superficial and deep dentin can be either the different quality of the substrate, as the authors concluded, or due to different $\mathrm{K}_{\mathrm{t}}$ between the groups, or both.

Recently, the stick shaped specimens have also been explored in the literature, as pointed out by Meira et al. (2004), since they have advantages such as the possibility to obtain a large number of specimens per tooth and the chance to eliminate the critical step of the confection of the notch. Since the cross section is the same throughout the specimen, the stress concentration at the stick interface $\left(\mathrm{K}_{\mathrm{t}}=1.5\right.$ and 1.3$)$ is usually smaller than that at the interface of the hour-glass specimens.

It is worth to highlight that the achievement of the same value for $\mathrm{K}_{\mathrm{t}}$ with different specimens, as for hour-glass with radius $1 \mathrm{~mm}$ and $h_{d}=3.75 \mathrm{~mm}$ (Table 1 cell A8) and stick with $h_{d}=1 \mathrm{~mm}$ (Table 1 cell A9), does not guarantee that the specimens will behave similarly. Many other considerations, such as the level of shear stress along interface, which are out of the scope of this work, should be considered.

Table 2. Bond strength (su), standard deviation (SD), variation coefficient (VC) and percentage of cohesive fractures for the adhesive Single Bond, for specimens with stick-shape (S) or hour-glass shaped with rectangular cross section (HR).

\begin{tabular}{|l|c|c|c|c|c|}
\hline \multicolumn{1}{|c|}{ Author } & Shape & $\begin{array}{c}\sigma_{u} \\
(\mathrm{MPa})\end{array}$ & SD & VC & $\begin{array}{c}\text { Cohesive } \\
\text { fractures } \\
(\%)\end{array}$ \\
\hline $\begin{array}{l}\text { Nunes, Swift } \\
\text { and Perdigao } \\
(2001)\end{array}$ & $\mathrm{S}$ & 75.9 & 15.3 & 20.2 & 50 \\
\hline $\begin{array}{l}\text { Hashimoto et al. } \\
\text { (2001) }\end{array}$ & $\mathrm{S}$ & 62.1 & 18.2 & 29.3 & 64 \\
\hline $\begin{array}{l}\text { Paul et al. } \\
\text { (1999) }\end{array}$ & HR & 40.2 & 9.7 & 24.0 & $*$ \\
\hline $\begin{array}{l}\text { Okuda et al. } \\
\text { (2001) }\end{array}$ & HR & 45.5 & 15.2 & 33.4 & $0 * *$ \\
\hline $\begin{array}{l}\text { Zheng et al. } \\
\text { (2001) }\end{array}$ & HR & 34.0 & 3.1 & 9.1 & $* * *$ \\
\hline $\begin{array}{l}\text { Pereira et al. } \\
\text { (2001) }\end{array}$ & HR & 36.7 & 11.4 & 31.0 & $*$ \\
\hline $\begin{array}{l}\text { Nakajima et al. } \\
\text { (2000) }\end{array}$ & HR & 49.9 & 10.6 & 21.2 & $*$ \\
\hline
\end{tabular}

** All fractures were classified as adhesive or mixed.

*** Fractures predominantly adhesive. 
Since $\mathrm{K}_{\mathrm{t}}$ is lower in stick shaped specimens, the nominal strength tends to be more representative and higher than for hourglass. Table 2 presents a comparison of bond strength of the dental adhesive Single-Bond $\AA-3 M$, with specimens with hour-glass or stick-shape. It is worth noting that the specimens with stick-shape normally present higher values of $\mathrm{K}_{\mathrm{f}}$.

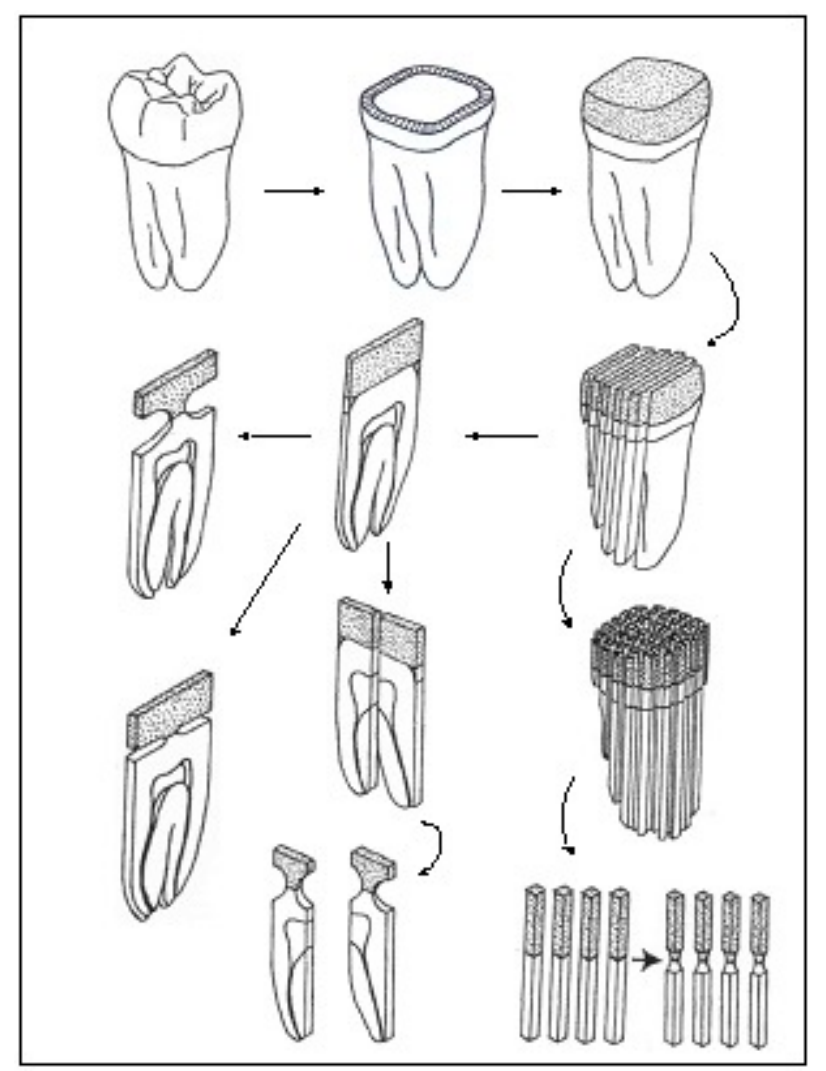

Figure 4. Notch shapes which can be used in microtensile tests, varying from a narrow slot to a smooth curvature (Modifed from Pashley et al. (1999)).

On the other hand, as observed in experimental works, higher frequency of cohesive fractures in dentin or resin are observed when stick shaped is used for the specimen (see Table 2). These data are coherent with the $K_{f}$ values obtained in the current work, when comparing cells B1 to B8 with cells B9 and B10, in Table 1. Thus, for cases with bond strength near to tensile strength of one of the substrates the hour-glass shaped is considered, by the authors, the best choice for the specimens.

\section{Conclusions}

1 - Variations in the specimen geometry can be responsible for part of the different bond strength values obtained in microtensile tests.
2 - Stick-shaped specimens tend to concentrate less stresses in the bonding interface, but lead to high stresses outside the interface area, thus favoring cohesive failures.

3 - In order to avoid cohesive fractures and to obtain favorable values of $\mathrm{K}_{\mathrm{t}}$, hour-glass shaped specimens with a curvature radius of $\mathrm{r}=1 \mathrm{~mm}$ seem to be more advantageous to test bonding interfaces.

\section{References}

Sano H., Shono T., Sonoda H., Takatsu T., Ciucchi B., Carvalho R., et al. "Relationship between surface area for adhesion and tensile bond strength--evaluation of a micro-tensile bond test". Dent Mater 1994; Vol. 10, No. 4, pp. 236-40.

Pashley D. H., Carvalho R. M., Sano H., Nakajima M., Yoshiyama M., Shono Y., et al. "The microtensile bond test: a review". J Adhes Dent 1999; Vol. 1, No. 4, pp. 299-309.

Oilo G. "Bond strength testing--what does it mean?" Int Dent J 1993; Vol. 43, No. 5, pp. 492-8.

Watanabe I., Nakabayashi N. "Measurement methods for adhesion to dentine: the current status in Japan". J Dent 1994; Vol. 22, No. 2, pp. 67-72.

DeHoff P. H., Anusavice K. J., Wang Z. "Three-dimensional finite element analysis of the shear bond test". Dent Mater 1995; Vol. 11, No. 2, pp. 126-31.

Versluis A., Tantbirojn D., Douglas W. H. "Why do shear bond tests pull out dentin?" J Dent Res 1997; Vol. 76, No. 6, pp. 1298-307.

Sudsangiam S., van Noort R. "Do dentin bond strength tests serve a useful purpose?" J Adhes Dent 1999; Vol. 1, No. 1, pp. 57-67.

Van Noort R., Noroozi S., Howard I. C., Cardew G. "A critique of bond strength measurements". J Dent 1989; Vol. 17, No. 2, pp. 61-7.

Van Noort R., Cardew G. E., Howard I. C., Noroozi S. "The effect of local interfacial geometry on the measurement of the tensile bond strength to dentin". J Dent Res 1991; Vol. 70, No. 5, pp. 889-93.

Sano H., Ciucchi B., Matthews W. G., Pashley D. H. "Tensile properties of mineralized and demineralized human and bovine dentin". J Dent Res 1994; Vol. 73, No. 6, pp. 1205-11.

Meira J. B., Souza R. M., Driemeier L., Ballester R. Y. "Stress concentration in microtensile tests using uniform material". J Adhes Dent 2004; Vol. 6, No. 4, pp. 267-73.

Inoue S., Van Meerbeek B., Abe Y., Yoshida Y., Lambrechts P., Vanherle G., et al. "Effect of remaining dentin thickness and the use of conditioner on micro-tensile bond strength of a glass-ionomer adhesive". Dent Mater 2001; Vol. 17, No. 5, pp. 445-55.

Nunes M. F., Swift E. J., Perdigao J. "Effects of adhesive composition on microtensile bond strength to human dentin". Am J Dent 2001; Vol. 14, No. 6, pp. 340-3.

Hashimoto M., Ohno H., Kaga M., Endo K., Sano H., Oguchi H. "Fractographical analysis of resin-dentin bonds". Am J Dent 2001; Vol. 14, No. 6, pp. 355-60.

Paul S. J., Welter D. A., Ghazi M., Pashley D. "Nanoleakage at the dentin adhesive interface vs microtensile bond strength". Oper Dent 1999; Vol. 24, No. 3, pp. 181-8.

Okuda M., Pereira P. N., Nakajima M., Tagami J. "Relationship between nanoleakage and long-term durability of dentin bonds". Oper Dent 2001; Vol. 26, No. 5, pp. 482-90.

Zheng L., Pereira P. N., Nakajima M., Sano H., Tagami J. "Relationship between adhesive thickness and microtensile bond strength". Oper Dent 2001; Vol. 26, No. 1, pp. 97-104.

Pereira P. N., Okuda M., Nakajima M., Sano H., Tagami J., Pashley D. H. "Relationship between bond strengths and nanoleakage: evaluation of a new assessment method". Am J Dent 2001; Vol. 14, No. 2, pp. 100-4.

Nakajima M., Kanemura N., Pereira P. N., Tagami J., Pashley D. H. "Comparative microtensile bond strength and SEM analysis of bonding to wet and dry dentin". Am J Dent 2000; Vol. 13, No. 6, pp. 324-8. 